\title{
KioskAR: An Augmented Reality Game as a New Business Model to Present Artworks
}

\author{
Yoones A. Sekhavat \\ Faculty of Multimedia, Tabriz Islamic Art University, Hakim Nezami Square, Azadi Boulevard, Tabriz, \\ East Azerbaijan 51647-36931, Iran \\ Correspondence should be addressed to Yoones A. Sekhavat; sekhavat@tabriziau.ac.ir
}

Received 26 October 2015; Revised 28 January 2016; Accepted 21 February 2016

Academic Editor: Ali Arya

Copyright (C) 2016 Yoones A. Sekhavat. This is an open access article distributed under the Creative Commons Attribution License, which permits unrestricted use, distribution, and reproduction in any medium, provided the original work is properly cited.

\begin{abstract}
This paper presents the architecture of KioskAR, which is a pervasive game implemented using augmented reality (AR). This game introduces a new business model that makes it possible for players to present their artworks in virtual kiosks using augmented reality, while they are having fun playing the game. In addition to competition between the players in the game, this game requires social interaction between players to earn more points. A user study is conducted to evaluate the sense of presence and the usability of the application. The results of experiments show that KioskAR can achieve a high level of usability as well as sense of presence.
\end{abstract}

\section{Introduction}

Recent years have witnessed a widespread success of computer games as cultural and commercial phenomena. The computer games market is a fast growing market that is reported to reach $\$ 128$ billion by 2017 [1]. In physical realworld games, players can navigate and communicate with each other in natural ways. This is an advantage of these games, in which the interface with the real-world is intuitive. On the other hand, providing sophisticated and animated contents that can be fantastic or even impossible in the realworld is an advantage of computer games [2].

Traditionally, computer games are locked within the confines of a computer or a smartphone display [3]. In these games, small windows provide a view into the virtual game world, where the player is disconnected from the surrounding physical environment. Pervasive games are a new type of digital games that have recently emerged and attracted academic attention. In pervasive games, players occupy a game world that is present within the ordinary world [4]. These games by extending the gaming experience out into the real-world make it possible for players to move with their smartphones in a room, street, or wilderness. Pervasive games incorporate the real-world in the game so that common objects from everyday life can become a part of the game. In this setting, players may have to walk to the place where an object resides in order to play the game. This is an important advantage of pervasive games that is not possible in traditional computer games [5].

Different techniques can be used to implement pervasive games. In Alternate Reality Games (ARG) [6], the real-world is used as a platform, in which multiple media and game elements are employed to create a storyline that infiltrates real life. In these games, story elements are spread throughout the players' information space, which are used by players to participate in building the story. In ARGs, the information space of players is Web sites, email messages, and physical locations. In situated games that are deeper rooted within a context, players must physically attend in a location designed for the game to participate in the game. Urban games such as Songs of North [7] are examples of situated games that depend on contextualized play. Pervasive games can also be implemented using augmented reality (AR) to bridge the gap between real-world games and computer games. Augmented reality has introduced new ways of interacting with digital contents, where real-world interaction and computercontrolled contents are mixed seamlessly. This introduces a new class of games, in which the physical environment becomes an integral part of the game. AR games make it possible to create a new game environment, where virtual objects are overlaid on the real-world. 
The focus of this paper is on a pervasive game based on augmented reality. Unlike virtual reality, which is an artificial and computer-generated view of a real life environment, augmented reality is the blending of virtual reality and real life that layers computer-generated multimedia on existing reality. In the recent years, various industries such as entertainment, e-commerce education, psychology, navigation, and tourism increasingly use augmented reality. According to Gartner research group, AR will be one of the top ten disruptive technology trends for the coming years that will result in considerable changes in relations between consumers and producers [8]. Acquisition of Metaio (an Augmented Reality Company) by Apple, Google's investment in Google Glass (an optical AR head-mounted display), and Microsoft efforts to produce Microsoft HoloLens show the significance of augmented reality in future applications. Augmented reality (AR) redefines the retail experience by boosting e-commerce in multiple ways and makes it possible for brands to differentiate themselves from competitors.

Digital games based on augmented reality have the potential to change the business models. AR by bringing $360-$ degree product views and enabling consumers to virtually visualize products in their homes can increase the likelihood of a purchase. Either at a retail store or in a website, AR makes it possible for consumers to experience the products before making purchase decisions. Using AR, customers can virtually try on a product and experience how garments look on them. A recent research in advertising shows that representing 3D models of products to customers in online shopping results in more product knowledge, better brand attitude, and, consequently, an increase in the purchase intention [9]. Augmented reality, by blurring the line between real and computer-generated worlds, provides additional information for buyers that is realized by visualizing virtual objects in the real-world on the screen.

This paper outlines a game with an augmented reality (AR) interface that allows art students to compete and collaborate with each other in a pervasive game, while presenting their artworks to other players. Artworks can be any handcraft made from wood, metal, clay, bone, horn, glass, paper, leather, stone, or other materials. Paintings, typographies, and other forms of $2 \mathrm{D}$ arts can also be presented in this game. In the AR game we propose, which is called KioskAR, virtual kiosks are established using augmented reality in physical places. KioskAR is a mobile application that employs the built-in cameras in devices to capture a user's physical world in real time, augments camera view with layers of multimedia contents (including 3D models, videos, and photos of artworks), and makes it possible for users to interact with these multimedia contents (viewing the artworks from different viewing angles, leaving comments on the artworks, and playing the slide shows).

During the game, players (i.e., art students) are encouraged to establish virtual kiosks. Kiosk owners can present their artworks through these virtual kiosks in forms of 3D models, videos, or slide shows of photos. Players by attending near the physical spot of a kiosk can visit this kiosk. They can physically turn around a virtual kiosk to see the kiosk as well as artworks in the kiosk from different viewing angles.
This is provided by augmented reality technology, where the synthesized images of artworks and virtual kiosks are shown on the image captured by the built-in cameras of a handheld device. Several sensors of the devices including GPS, accelerometer, and compass are used to decide how this multimedia content must be shown to a player. Kiosk owners can physically stand near the physical spot of their kiosk to meet visitors and explain their artworks. However, the artworks are visible to visitors even if the owners are not there. This game values social behaviors by encouraging team work. Players earn more score when playing in a team. An integral part of this game is mobility, where players need to physically explore the environment looking for virtual kiosks. In this application, a user or a group of users must be positioned at predefined spots to view and interact with virtual and computer-generated multimedia content. The results of interaction are shared and spread out on all AR devices.

This paper discusses technical challenges, usability issues, and the sense of presence in AR game design and proposes the KioskAR game that

(i) makes it possible for players to present their artworks in virtual kiosks that are visible in real geolocation spots through augmented reality;

(ii) promotes real social interactions between players through prioritizing group activities to individual activities;

(iii) employs various encouraging factors to get players more involved in the game.

\section{Augmented Reality Games}

The design of a pervasive game based on augmented reality requires considering many issues including the architecture of pervasive games, social interactions between players, and AR tracking techniques that are discussed in the following.

\subsection{Pervasive AR Games}

2.1.1. Overview. In [4], the pervasive mobile game is defined as "a context-aware game that necessarily uses mobile devices." Context-awareness involves sensing the environment such that the gameplay is adapted based on the current sensed conditions. This sensed data provides a source for game content and customized behaviors. In pervasive games, players are mapped onto real-world settings such that they must literally move from place to place to control their avatars (e.g., Human Pacman [10] and ARQuake [11]). In pervasive mobile games, the world boundary is not welldefined and, sometimes, it can be unconstrained. Players are called colocated, when they can interact inside an area defined by a local network. A pervasive game may last for several weeks or months, affecting the daily lives of players. This requires creating a persistent world that progresses without the player's intervention, while notifying the player to take an action if some event happens [12]. Players can access remote resources, while they are located anywhere. 
2.1.2. Related Work. A survey of existing pervasive games and their technologies is provided in [13]. The chase game Can You See Me Now? [14] allows the interaction between real players on a city street with online players in a parallel virtual city. In Gbanga, virtual world is connected to the real-world locations visited by the player. This game involves walking around the city, moving between different areas, exploring new places, finding items, and meeting with other players. In Uncle Roy All Around You [15] and PAC-LAN [16], players are required to literally go to specific physical locations to complete the game activities.

IPerg [17] (Integrated Project in Pervasive Gaming) is a European research project with the focus on extending gaming experiences in spatial, social, and temporal dimensions. In GPS Mission, players are guided to checkpoints, where they can find virtual gold used to claim special virtual trophies. In this game, players leave marks to show they have already visited that place. In REXplore [18], which is a game designed for tourists, location information is used to encounter players with historical figures associated with historical buildings. In Insectopia [19], players run about to collect virtual insects, which are traded between players. In this game, players compete and collaborate in pairs in order to collect more insects. In UbiFit Garden [20], gamification is employed to sense physical activities of players and make the virtual garden blossom. In Fish'n'Steps [21], players feed a virtual fish to grow.

In AR-Bowling [22], players throw virtual bowling balls using hand gestures detected by pinch gloves. In AR pingpong [23], players receive force feedback through optically tracked ping-pong racket handles. In [24], which is an AR game performed in a tracked area, a player moves around this area to collect treasures. ARQuake [25] is a multiuser game, in which the player is positioned in the real-world (tracked by an AR marker, a GPS sensor, and a digital compass). In this game, the player moves around shooting monsters to collect items. TimeWarp uses certain historical or cultural locations related to the environment in which the game is played. NetAttack [26] is an indoor/outdoor AR game that employs GPS and other tracking techniques to localize game objects. The Rooms [27] is a collaborative horror game in which the projected augmented reality is used to support collaborative immersive gaming.

Some pervasive games have been proposed with educational purposes. In [28], students play the role game of hunting as lions in groups on a school playing field. The purpose of this game is to encourage learning through highly physical role play. Gigaputt helps players to learn a threehole golf course, in which the player's location is tracked. In this game, after teeing off, players physically move to where their virtual balls have landed while retracing their paths. Playful Toothbrush [29] is an educational game designed to encourage children for proper brushing habits.

2.2. AR Design for Social Interaction. Participation in a social activity, which the players can enjoy with their friends, is one of the important parameters of creating fun in digital games [30]. Pervasive games by focusing on the social aspects of computer games preserve the rich social interactions found in traditional games (Pirates [31] and STARS [32]). These games are played across different media channels (e.g., smartphones) that make it possible to explore mixed reality environments. Through these games, the social quality of traditional games is integrated with computer games.

The design of an AR game that involves the collaboration of participants must deal with some changes. In these games, participants share a physical space surrounding them as well as the virtual space bounded to the physical space. Although social interaction in game design is not unique to AR game design, employing this technology provides new opportunities to design novel forms of social interaction in digital games [33]. More specifically, AR can provide a new environment in which virtual and real social interaction between the players can simultaneously occur in the game environment. To engage in a colocated activity or a virtual social interaction, players can perform physical movements, which may require implementing effective interface metaphors. Tracking and communication is another important requirement in AR game design. In BragFish [34], AR technology is used to create a shared virtual space in a fishing game, which results in social interaction among the players. In this game, physical actions are employed to allow players to gain situation awareness. In Art of Defense [35], by moving of tangible objects, players collaborate to defend their bases. In this game, players in the same place perceive the physical presence of others. A team-based competitive AR game is proposed in [2], in which players physically explore the game environment, while communicating with other players.

2.3. Location-Based versus Marker-Based AR. Mobile AR applications are classified into marker-based and locationbased AR that differ in the techniques used to track and sense the environment [36]. In location-based AR, which is generally used outdoor, sensors such as GPS, compass, and gyroscope are used to indicate the location of a user. This geolocation data indicates what multimedia content must be rendered over the camera view. Arusma (https://www .aurasma.com/) and Layar (https://www.layar.com/) are examples of location-based AR applications. On the other hand, in marker-based AR, easily detectable and predefined target images are used to register the position of data that is augmented. In marker-based AR, the rotation and translation of the image detected in relation to the camera of the smartphone indicate where to augment data.

In pervasive games based on location-based AR, sensors such as GPS and compass and accelerometer provide information about the current context of players employed to deliver a gaming experience. This information is changed based on location, action, and feelings of the players [28]. However, some difficulties may decrease the usability of this technique. Location-based AR applications not only are resource-intensive but also are limited due to sensor accuracy [37] (GPS accuracy is anywhere between 10 and 50 meters and compass data is only accurate to around 20 degrees) [38]. Techniques have also been proposed to interact with virtual contents in the real-world. The interaction with the environment can be achieved through automatically detecting the 
environment by location sensors, gesture identification, or speech recognition.

AR games can be marker-based such that the game environment is activated when scanning a marker (already registered to the AR game) by the built-in camera of the device. This way, the game environment and the game objects appear on the marker when the player looks through the camera of the device. On the other hand, in location-based games (a.k.a., markerless AR games), GPS, compass, and gyroscope sensors indicate when and how to augment virtual objects on the screen. The KioskAR we propose in this paper is a markerless AR game that employs GPS, accelerometer, and compass data to indicate where and from what direction to show virtual kiosks.

\section{Game Design}

KioskAR is a social game, which bridges the gap between real and virtual social behavior. The students of art universities are target players of this game. Through the game, players compete with each other to receive more points to enhance their kiosk, while at the same time, they collaborate with other players to receive more points. This game makes it possible for players to present their artwork through a virtual kiosk presented in a physical place using augmented reality. This game implements a dimension of social interaction through cooperation with players to create an amusing gaming experience. Players can employ KioskAR to facilitate existing social interaction in groups to which they belonged. The more involvement in the game, the more credit for players that can be used to enhance virtual kiosks.

3.1. KioskAR Scenario. A player receives a predefined initial credit once he/she registers to the game. Using this credit, the player is able to establish a new virtual kiosk. Kiosks can be established in open areas on the campus. To establish a kiosk, a player must stand physically in the spot he/she wants to establish a kiosk and indicate the direction from which the kiosk is visible through the camera view. A kiosk can be established in spots where there is no overlap with the boundaries of other kiosks. A kiosk is visible to a player when this user stands nearby the geographical location of that kiosk, and through the built-in camera of the device, the player looks at the direction where the kiosks are located. This way, the virtual kiosk is augmented on the image captured by the camera of the device.

Kiosk owners can present their artworks in terms of 3D models, videos, or slide shows of photos. Players can physically turn around a kiosk and see the kiosk as well as artworks in the kiosk from different viewing angles. These features of augmented reality presentations are achieved by employing compass, accelerometer, and GPS sensors of a smartphone. Kiosk owners can physically stand near the physical spot of their kiosk to meet visitors and explain their artworks. However, the artworks are visible to visitors even if the owners are not there.

A player receives credits when (1) he/she regularly updates his/her kiosk through adding new 3D models, videos, and photo collections of artworks, (2) he/she hangs around the physical spots of other kiosks and regularly visits them, (3) either the player views other players' works or others view the player's work, and (4) either the player leaves comments on artworks of other kiosks or others leave comments on the player's work. To promote the real social interaction between players, simultaneously visiting the kiosks in a group results in receiving more credits. The more credit a player gains, the more new kiosks this player can open in the campus. Although there is no limit on the number of kiosks a player can establish, the cost of opening new kiosks is increased exponentially to prevent dominating the physical area by some specific players.

Since the visibility of a kiosk depends strongly on the traffic of people in the physical spot of that kiosk, kiosks can be traded between players. In other words, some players might like to spend their credit to establish new kiosks in neighborhoods where people tend to hang out. There are also virtual bulletins that are visible using augmented reality located in some predetermined areas on the campus. Players can use their credit to advertise their kiosks on the bulletin.

3.2. KioskAR Overview. The overall architecture of the KioskAR including user interface (UI), communication (CM), game engine (GE), and data access (DA) components is presented in Figure 1. As shown in this figure, five main parts of the interface of KioskAR that appear in client side are map view, AR view, kiosk view, spot view, and configuration view. The overall process model of KioskAR including activities that are performed while playing the game as well as activities to configure the virtual kiosks is shown in Figure 2.

3.2.1. Map View. Map view provides a 2D map of the playing environment and the locations of kiosks. This view presents a big picture of the campus and kiosks that are already established on the campus. A snapshot of the map view for IAU (http://www.tabriziau.ac.ir/) campus (which is also used in our user study) is shown in Figure 3. To reduce visual search time, a good color coding is crucial. In map view, colors are selected based on "opponent" process theory of colors [39], which is widely used in information visualization [40]. According to this theory, red versus green, blue versus yellow, and black versus white are three opponent color pairs. Each color in a pair can be easily distinguished from the other color. Using this theory, the background of the map view is pale yellow, while Kiosks that are already established in the campus are shown by blue kiosk logos. Grey areas on this map are indoor places that cannot be used to establish a kiosk. Similar to standard map views, players can zoom and pan the map view to explore the gaming environment. A user's position and orientation are shown on the map view. Kiosks are selectable in this map. Once a user clicks a kiosk icon on the map, a pop up window is displayed representing the certificate of this kiosk including the name of kiosk, the name of the owner, the picture of the owner, a brief description of what is represented in the kiosk, the popularity score of the kiosk, and the credit of the owner. The size of display font is compatible with the zooming scale. 


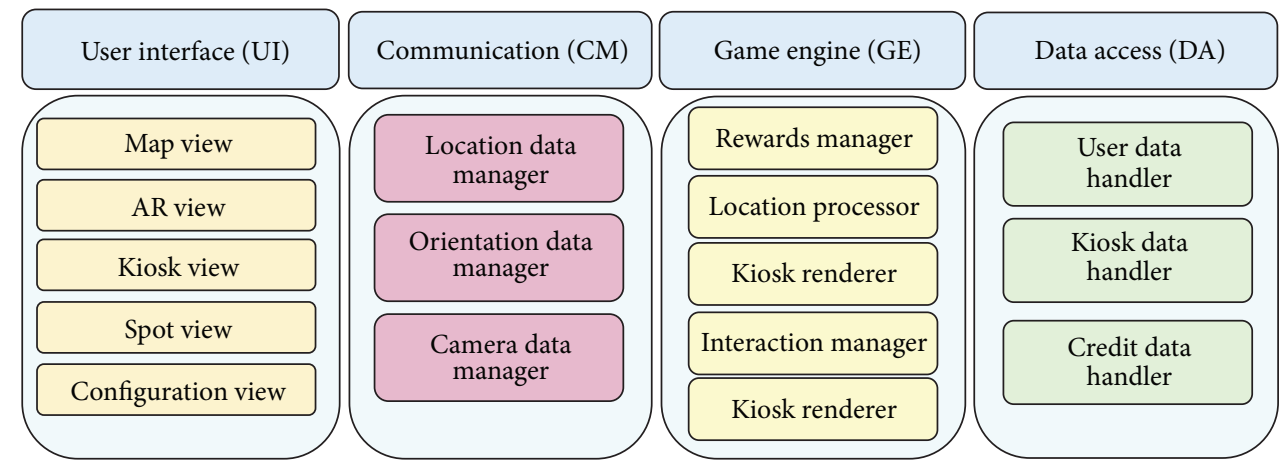

FIGURE 1: The architecture of KioskAR including client and server side components.

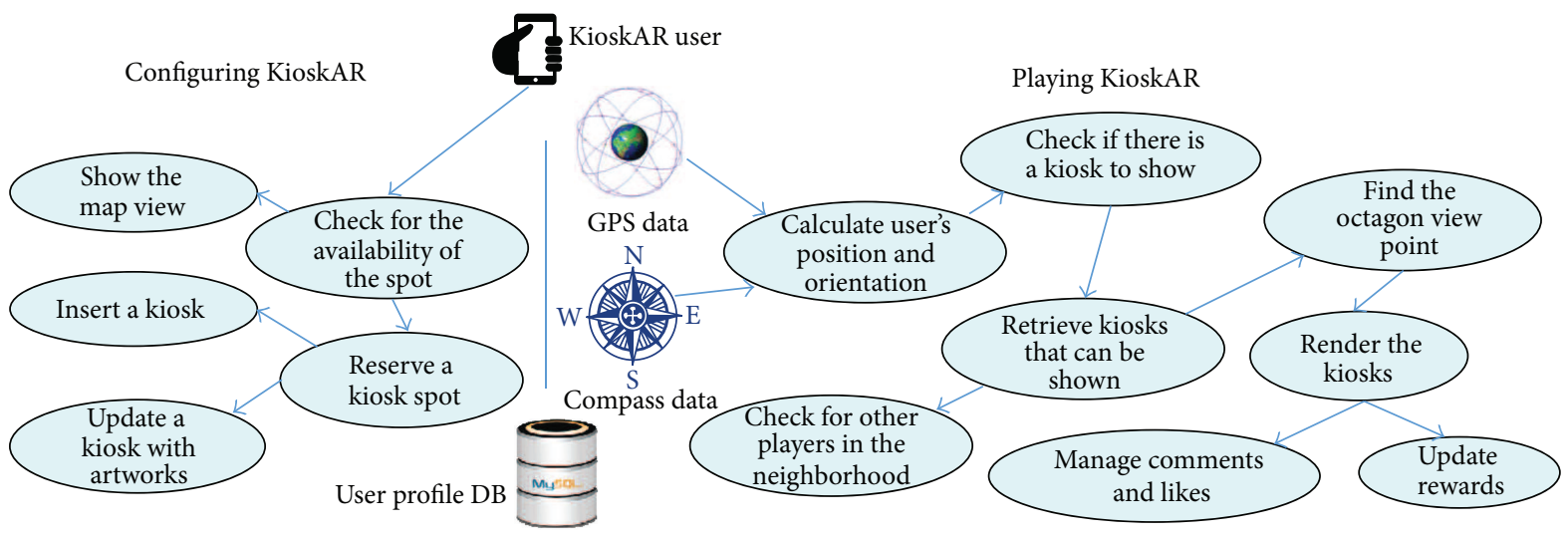

FIGURE 2: The overall process model of KioskAR including activities that are performed while playing the game as well as activities to configure the virtual kiosks.

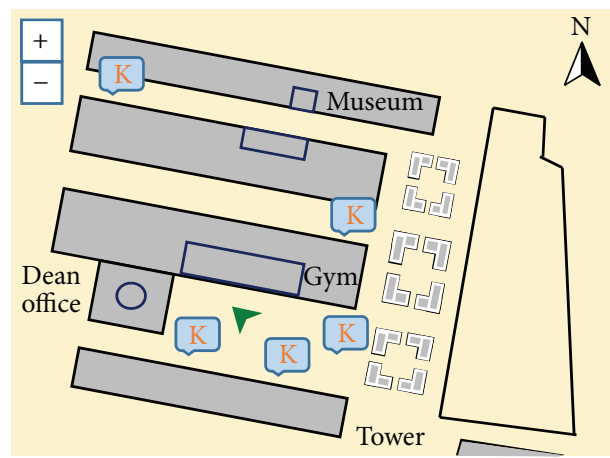

FIGURE 3: The map view of KioskAR including the available spots as well as spots that are already occupied by the kiosks.

3.2.2. AR View. AR view is the main view of KioskAR. If a player stands near the physical spot of a kiosk and looks through the AR view of the application, the $3 \mathrm{D}$ model of the kiosk is augmented on the image captured by the camera of the device (Figure 4). The goal of AR view is mixing real and virtual multimedia content to enhance the perception of a user from the current location and kiosks. There are six predetermined kiosk templates that can be selected by players. They all provide spots on the kiosks that can be used to put 3D models, videos, or photos of artworks. By clicking

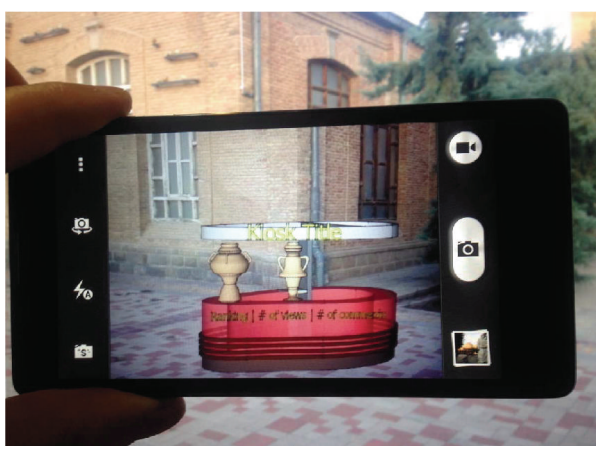

FIgURE 4: The 3D model of the kiosk is augmented on the image captured by the built-in camera of the device.

on an item on the AR view, a player can leave a comment for an item in that kiosk. Players can physically turn around a kiosk to see the kiosks from different viewing angles.

In marker-based AR, an image (already registered to an AR component) is used as a target image that activates an AR application. In this method, a user can turn around the target image to see the $3 \mathrm{D}$ model augmented on the image captured by the camera from different viewing angles (Figures 5 and 6). However, in location-based AR, we need to find a way to indicate from what viewing angle a player is looking at 


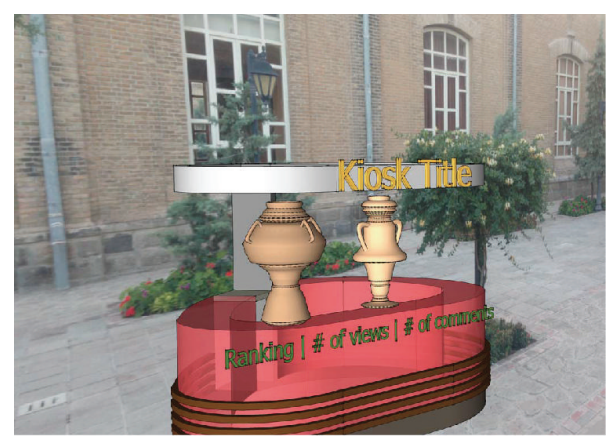

FIGURE 5: The AR view, watching at a kiosk from the north-east side of the kiosk.

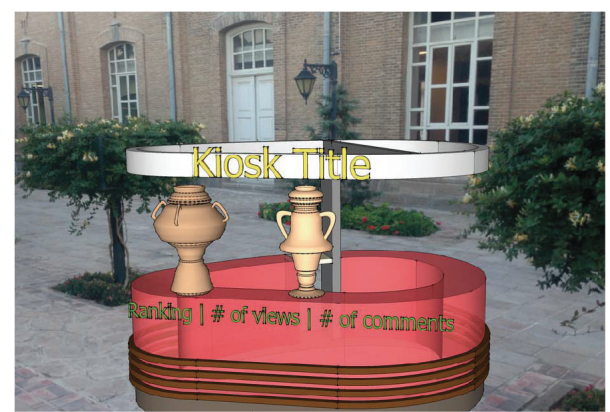

FIGURE 6: The AR view, watching at a kiosk from the north-west side of the kiosk.

a kiosk. To this end, we assume there exists a hypothetical octagon boundary around a kiosk (see Figure 8). Each side of this octagon indicates from what viewing angle a user is looking at the kiosk.

Let $p=\left(p_{x}, p_{y}\right)$ be the user's position on the 2D map of the game field. Given an octagon with the side size of $L$, where $s_{i}$ represents the side between $a_{i}$ and $a_{i+1}$ corners, we compute the distance from the user's position to all sides of octagon around the the kiosk.

We need to compute the distance from the user's position $p=\left(p_{x}, p_{y}\right)$ from the line between $a_{i}=\left(x_{i}, y_{i}\right)$ and $a_{j}=$ $\left(x_{j}, y_{j}\right)$. The vector perpendicular to the line between $a_{i}$ and $a_{j}$, denoted by $v$, and the vector from the point $p$ to the first point on the line between $a_{i}$ and $a_{j}$ are calculated as

$$
\begin{aligned}
& v=\left[\begin{array}{c}
y_{j}-y_{i} \\
-\left(x_{j}-x_{i}\right)
\end{array}\right], \\
& r=\left[\begin{array}{c}
x_{i}-p_{x} \\
y_{i}-p_{y}
\end{array}\right] .
\end{aligned}
$$

The distance from $p=\left(p_{x}, p_{y}\right)$ to the side $s_{i}$ (i.e., the line between $a_{i}$ and $a_{j}$ ) is given by projecting $r$ onto $v$ such that

$$
\begin{aligned}
& \operatorname{distance}\left(p, s_{i}\right)=|\hat{v} \cdot r| \\
& =\frac{\left(x_{j}-x_{i}\right)\left(y_{i}-p_{y}\right)-\left(x_{i}-p_{x}\right)\left(y_{j}-y_{i}\right)}{\sqrt{\left(x_{j}-x_{i}\right)^{2}+\left(y_{j}-y_{i}\right)^{2}}} .
\end{aligned}
$$

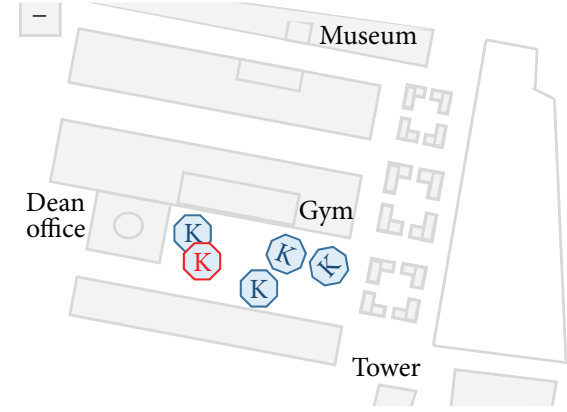

FIgURE 7: The spot view allows specifying the physical location of a new kiosk. Overlapping boundaries are shown in red.

By computing the distances from a user's position $\left(p_{x}, p_{y}\right)$ to different sides of the octagon $\left(s_{i} \in S\right)$, the side with the minimum distance to player's position is selected as a view that is shown to user. The selected side is changed when the players move around the kiosk and the distances to different sides are changed:

$$
\text { selected edge }=\underset{s_{i} \in S}{\operatorname{argmin}} \operatorname{distance}\left(p, s_{i}\right) .
$$

3.2.3. Spot View. A kiosk can be established in a spot where there is no overlap between the boundary of this kiosk and other existing kiosks. This view shows the boundary of existing kiosks in terms of octagons on the map and the boundary of the new kiosk to be established. The boundary of the new kiosk is shown in green, which turns into red in case there is an overlap with the boundaries of existing kiosks (see Figure 7).

3.2.4. Kiosks View. To establish a new kiosk, the kiosk view makes it possible to browse different kiosk templates already available for the players. In the first version of KioskAR, users can select among six default kiosks (four of them are shown in Figure 9). The 3D models of kiosks are obtained from sketch up warehouse (https://3dwarehouse.sketchup.com/) with slight changes to show scores, rankings, and comments on the kiosks. All kiosks provide facilities to present artworks in forms of 3D models, photos, videos, and audios. However, kiosks have different capacities to upload such multimedia. Depending on the features of these kiosks, players require different ranges of credits to establish the kiosks.

3.2.5. Configuration View. The configuration view of KioskAR provides a wide variety of features including registration and editing profile information. In this section, users can also exchange real money for credits or trade their kiosks with other players. Some hot spots (not all of them) are already reserved by the game engine which require more credit to be purchased by the players. This encourages those who are new to the game to exchange credits with real money to accelerate their progress in the game. This view also shows the statics of top players including players who own hot kiosks, players with top credits, and players with more views 

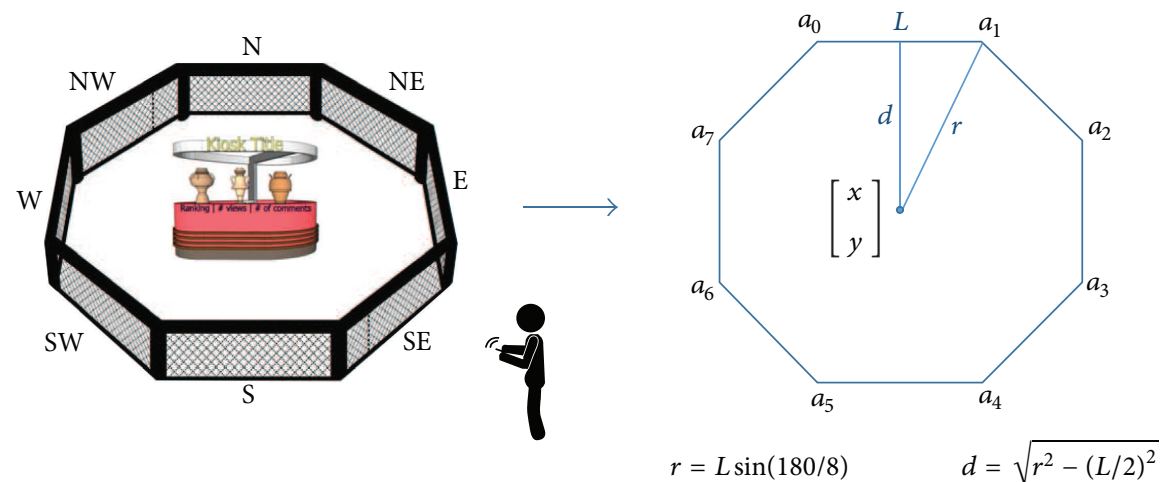

$$
\begin{array}{ll}
a_{0}=\left[\begin{array}{c}
x-L / 2 \\
y+d
\end{array}\right] & a_{4}=\left[\begin{array}{c}
x+L / 2 \\
y-d
\end{array}\right] \\
a_{1}=\left[\begin{array}{c}
x+L / 2 \\
y+d
\end{array}\right] & a_{5}=\left[\begin{array}{c}
x-L / 2 \\
y-d
\end{array}\right] \\
a_{2}=\left[\begin{array}{c}
x+d \\
y+L / 2
\end{array}\right] & a_{6}=\left[\begin{array}{c}
x-d \\
y-L / 2
\end{array}\right] \\
a_{3}=\left[\begin{array}{c}
x+d \\
y-L / 2
\end{array}\right] & a_{7}=\left[\begin{array}{c}
x-d \\
y+L / 2
\end{array}\right]
\end{array}
$$$$
r=L \sin (180 / 8)
$$

FIGURE 8: A hypothetical octagon around the kiosk. A side having minimum distance from the user's position is selected as a view from which the kiosk is shown to the user.
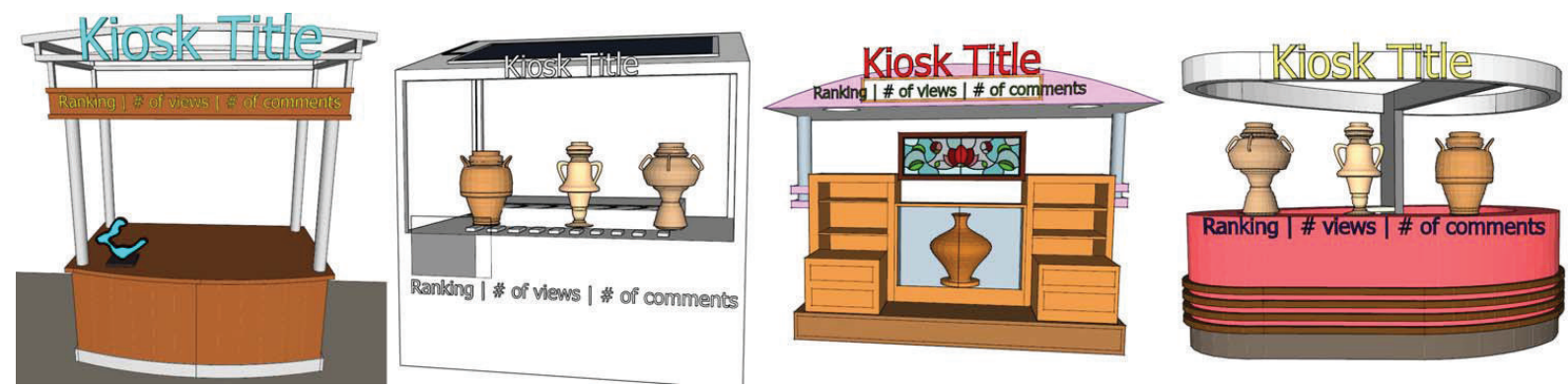

FIGURE 9: A snapshot of four different default kiosks used in KioskAR. The user selects one of these kiosks once establishing a virtual kiosk.

and comments. The configuration view allows users to post information of their kiosks in the news bulletin of the game to encourage players to be involved in the game.

3.2.6. Credit Collection Module. A player receives the initial credit of 1000 points once he/she registers to the game. Although a basic kiosk can be established by this credit, a player needs more credit to enhance the kiosk or to establish other kiosks. Each view from other visitors (that requires visiting the physical location of the kiosk and seeing the kiosk through augmented realty) is one point for the kiosk owner and visitor. There is a limit of one view per kiosk per day, unless the kiosk is updated between the views. When a visitor leaves a comment during the visit to a kiosk, both the visitor and the kiosk owner receive extra two points.

To promote real social collaboration, visitors who visit in groups receive more points. More specifically, $n$ players simultaneously visiting a kiosk each receive $n$ points. This way, we promote real social collaboration between players, which is one of the goals of this game. An update in the kiosk is five points, which is limited to one update per day. The progress in the game is achieved through finding the right spots to establish your kiosk, opening kiosks near well-known kiosks, using and representing good artworks in kiosks, and regularly updating the kiosks.

3.2.7. Technical Requirements. KioskAR is an Android location-based mobile game which can be installed on smartphones and tablets. This game requires awareness of the location (using GPS sensor) and the orientation (using compass and accelerometer) of the devices. Obviously, an AR application requires a built-in camera of the device to present the real-world onto the device's screen. On the server side of the application, MySQL is used to store a player's profile, the multimedia presented in virtual kiosks, and the status of the game and players. In KioskAR, players can view and interact with multimedia provided by other users. This requires the server side processing of interactions in the game and updating all users with the latest state of the game. The blackboard communication model is used in KioskAR where players receive the updated information directly from the server, without P2P correspondences between the players.

\section{Evaluation Methodology}

As discussed in [41], user experience in augmented reality has not been studied appropriately. Although various design choices are made into design and development of KioskAR, the true value of this application is verified using a user study. KioskAR was designed to virtually present artworks in real physical locations through an augmented reality game, where players compete and socially collaborate to receive more scores. In this study, we aim to empirically measure qualitative data related to usability and sense of presence in order to make well-supported statements about the usefulness of KioskAR. 
4.1. Study Design. We asked participants to join the game and play for a period of two months. During this time, players were asked to play with KioskAR at least 3 times a week. The data of participants not engaging actively in the game during this period were eliminated from the results. Although all participants were compensated for their time to participate in this study, to encourage more activity, players with high activities and high scores were compensated with extra gift cards. Although these extrinsic rewards may impair the results of measuring the desirability of the KioskAR, we noticed this technique is effective to keep participants engaged in our long-term study. Another study without any extrinsic rewards can be useful to measure the desirability of KioskAR. However, this will need another form of motivation to keep participants engaged in the game.

We conducted a prestudy questionnaire to measure educational level, prior experience, and knowledge of participants with AR technology as well as social network games. We manually installed the game on participants' smartphones. We had a quick presentation session to teach participants how to use the application. Participants were told that their general information including location and usage information will be stored, when they are connected to Internet and the application is active. Before starting the study, we gained informed consent for participating in the study and gathering usage information. Participants were asked to complete questionnaires regarding usability and sense of presence two months after they played the game. They also completed a poststudy questionnaire which was designed to measure subjective reactions to the use of KioskAR.

4.1.1. Participants. A total of 56 participants including 24 males and 32 females were purposely recruited from the students of IAU University. Participants were asked to have experience of using smartphones. The prestudy questionnaire verified all participants have a similar level of knowledge of AR applications. The results of 8 participants were removed from the study for not actively playing the game. During the first week of study, few bugs were reported by participants that were fixed immediately, and we contacted participants to update the application.

4.2. Sense of Presence. As discussed in [42], the sense of presence is an important issue with regard to augmented reality games. Unlike virtual reality games, in which we aim to disconnect the player from the real-world, AR games require players to be present in the real-world as a game environment. In [43], presence is defined as "the subjective expression of being in one place or environment, even one is physically situated in another." As discussed in [42], presence can be stated in terms of physical (or spatial) presence and social presence. In [44], physical presence is defined as "the sense of being here." On the other hand, social presence is defined as "the sense of being together with another." Both physical and social presence are important factors in KioskAR. Physical presence is important because players must feel they are exploring a real kiosk. Social presence is important because a player must collaborate and interact with other players and kiosk owners to receive more points.
In spite of existing definitions of spatial and social presence, measuring presence is a challenging issue in AR games. As discussed in [42], level of interactivity and realism are two important factors affecting the sense of presence in AR games. Playing a game results in a higher sense of presence in comparison to observing a game. As discussed in [45], this interaction also results in a higher degree of entertainment. On the other hand, realism can be realized in several ways such as using first-person view instead of 3rd-person view, using real sounds and virtual representation of bodies. Presence has another side in collaborative games, where a player interacts with other players in addition to interaction with virtual world and objects. As discussed in [46], playing with a friend results in a better sense of presence in comparison to playing with a stranger. In KioskAR, players playing together share a mutual goal, which is trying to receive more points when the players visit kiosks in groups. To this end, players physically move as a team through the real-world. In this study, we aim to find how people feel towards the real and virtual elements.

There are several factors affecting the sense of presence from which the actual space where KioskAR is used has a significant effect on the sense of presence. Since the main goal of KioskAR is to help artists to present their artworks, the establishment of virtual kiosks in an artistic space can be crucial to ensure the visibility of the kiosks by target customers. What we measure in terms of sense of presence for KioskAR is the overall sense of presence by considering factors related to the application as well as the environmental parameters in which the application is used. Studying the effect of actual space on the sense of presence is a separate study that will be taken into account in future work.

4.2.1. Measures. MEC Spatial Presence Questionnaire (MECSPQ) [47] is a questionnaire to measure the sense of presence that covers several aspects of presence. This questionnaire is derived from a solid theory of spatial presence [48], which is designed to be filled by participants immediately after media exposure. Originally, variables including attention, involvement, suspension of disbelief, spatial situation model, and spatial presence are considered in this questionnaire. This questionnaire is widely adapted and used in the literature to measure the sense of presence for different media. In [42], to measure the presence experienced by players in an AR game, a questionnaire is proposed which is inspired by MEC-SPQ. The questionnaire we used in our experiments is adapted from the questionnaire in [42] which makes it possible to measure the sense of presence in terms of involvement, perceived interactivity, spatial presence, and social presence. The questions used to measure each of the four factors are shown in Table 1. Participants were asked to answer the questions that were rated on a 5-point Likert scale. Some of the statements in the original questionnaire were vague. Since the user study was conducted in Persian language, we made a clear and easy to understand translation of the statements.

4.2.2. Results. The results of experiments evaluating the sense of presence in terms of four different parameters including involvement, interactivity, spatial presence, and social 
TABLE 1: The statements used in the questionnaire to evaluate the sense of presence.

\begin{tabular}{ll}
\hline & Questions \\
\hline \multirow{l}{*}{ Involvement } & Q1: I thought most about things having to do with the game. \\
& Q2: I imagined precisely what the artworks were. \\
& Q3: I thought the game could have personal meaning for me. \\
& Q4: I considered things that were presented in the AR view. \\
& Q5: The experience activated my thinking. \\
\hline \multirow{2}{*}{ Interactivity } & Q1: I felt as if I could interact with virtual kiosks. \\
& Q2: I felt as if I could interact with virtual objects. \\
& Q1: At the end of the game, I felt as if I came back to reality. \\
& Q2: At the start of the game, I felt as if I were entering a new world. \\
& Q3: I felt as if I were part of a game that was not part of the reality. \\
& Q4: All my senses were stimulated by the (game) experience. \\
& Q5: The virtual objects felt real to me. \\
\hline \multirow{3}{*}{ Social presence } & Q1: I felt the presence of another person. \\
& Q2: I feel that the person is watching me and is aware of my presence. \\
& Q3: The person seemed alive to me. \\
& Q4: I perceived the kiosks as computer-generated images, not as a real. \\
& Q5: The thought that the kiosk was not real came often to my mind. \\
\hline
\end{tabular}

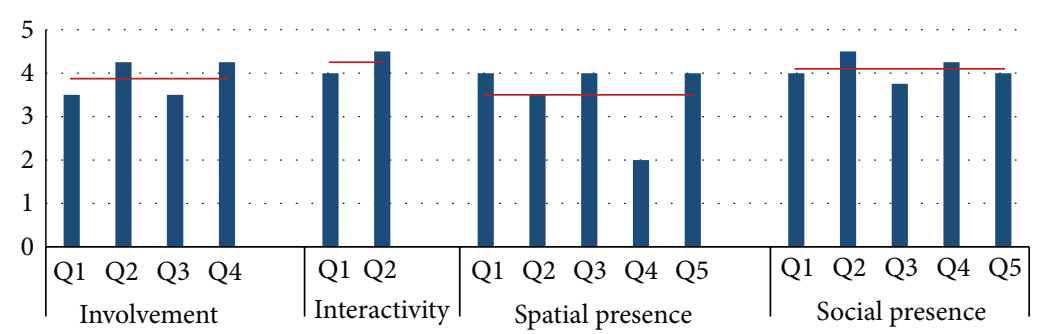

FIGURE 10: The average score of questions for the sense of presence questionnaire [42] answered by participants to measure the sense of presence in KioskAR.

presence are shown in Figure 10. As shown in this figure, KioskAR shows a high level of sense of presence according to the responses of participants (the average score greater than 4 for all parameters).

We were interested to find if players perceive game actions taking place within the real environment. We were also interested to know if the players feel the existence of virtual objects in the real-world. By analyzing the log data, we noticed that the strongest sense of presence was among the participants playing in a team, indicating the positive effect of social collaboration in the sense of presence. In particular, participants felt more sense of interactivity and social presence in the case of collaboration. One of the main challenges with an AR game is to provide continuous sense of presence to players. Participants reported that they felt they were in the game space, while navigating on the campus and visiting different kiosks.

4.3. Usability. Usability is an important factor in the evaluation of AR systems indicating how well users can exploit the functionalities of a system [49]. To study the usability of applications for handheld devices, Mobile Phone Usability Questionnaire (MPUQ) has been used in literature [50]. However, some specific issues related to augmented reality are not considered in MPUQ. In this paper, we employ Handheld Augmented Reality Usability Scale (HARUS) that includes comprehensibility and manipulability scales [49]. Comprehensibility refers to the "ease of understanding the information presented" by an AR application. On the other hand, the manipulability refers to "ease of handling AR application as user performs a task." As shown in Table 2, the HARUS questionnaire includes 16 statements (8 statements for comprehensibility scale and 8 statements for manipulability scale). Users were asked to answer to what extent they agree to the statements. We use a 5-point Likert scale ranging from strongly disagree to strongly agree.

Mixing positive and negative questions makes the respondents think more and avoid the tendency to tick the same response for every question [51]. More specifically, using a balance of negative and positive questions results in cautiously responding to the questionnaire. Obviously, to calculate the sum of scores for the questions, negatively worded questions were scored in a reverse manner.

4.3.1. Results. The result of applying HARUS questionnaire [49] on participants is shown in Figure 11. As expected, KioskAR shows a high level of comprehensibility according to the responses of participants. In terms of manipulability, 
TABLE 2: The statements used in HARUS questionnaire to evaluate usability.

\begin{tabular}{|c|c|}
\hline \multicolumn{2}{|c|}{ Questions } \\
\hline Comprehensibility & $\begin{array}{l}\text { Q1: Interacting with this application requires a lot of mental effort. } \\
\text { Q2: The amount of information displayed on screen was appropriate. } \\
\text { Q3: The information displayed on screen was difficult to read. } \\
\text { Q4: The information display was responding fast enough. } \\
\text { Q5: The information displayed on screen was confusing. } \\
\text { Q6: The words and symbols on screen were easy to read. } \\
\text { Q7: I felt that the display was flickering too much. } \\
\text { Q8: The information displayed on screen was consistent. }\end{array}$ \\
\hline Manipulability & $\begin{array}{l}\text { Q1: Interacting with KioskAR requires a lot of body muscle effort. } \\
\text { Q2: Using the application was comfortable for my arms and hands. } \\
\text { Q3: The device difficult to hold while operating the application. } \\
\text { Q4: It is easy to input information through the application. } \\
\text { Q5: My arm or hand became tired after using the application. } \\
\text { Q6: The application is easy to control. } \\
\text { Q7: I was losing grip and dropping the device at some point. } \\
\text { Q8: The operation of this application is simple and uncomplicated. }\end{array}$ \\
\hline
\end{tabular}

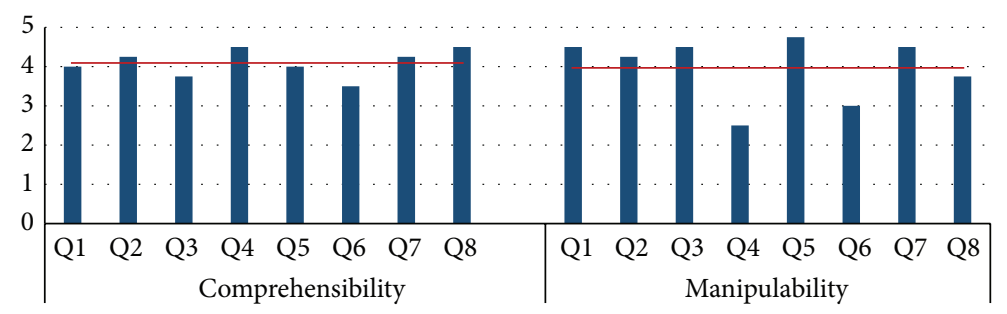

FIGURE 11: The average score of questions in HARUS questionnaire [49] answered by participants to measure the usability of KioskAR.

although the overall score is acceptable, the average of scores for Q4 (it is easy to input information through the application) and Q6 (the application is easy to control) are somehow low in comparison to other questions. We argue that this is a common problem to all AR applications designed for handheld devices. In these applications, a user needs to hold his/her device with one hand, while he/she may not have full control on the device, specifically when it is required to tap on the screen or to use the keyboard. Using headmounted augmented reality glasses can be a solution for this problem. However, this requires carrying this device while playing KioskAR, which may not be convenient for all users. An alternative solution for handheld devices can be fixing the kiosk in AR view such that it does not require the user to tap on the window or use the keyboard in the AR view.

\section{Conclusion}

In this paper, we proposed KioskAR, which is an AR game that allows students to present their artworks in terms of $3 \mathrm{D}$ models, videos, and photos in virtual kiosks. Virtual kiosks, which are augmented on the camera view of a handheld device, are visible to all players when they stand in predetermined locations. KioskAR is a location-based augmented reality application that employs GPS, accelerometer, and compass sensors to find geolocation information and the direction of players. KioskAR not only provides a novel business model through gaming but also encourages physical social interactions. To gain more points, players need to physically move as a team and visit virtual kiosks located in different spots on the campus.

A user study was conducted to evaluate the sense of presence as well as the usability of KioskAR. The results of experiments show that participants reported a high level of social presence in addition to spatial presence, involvement, and interactivity. During the study, we noticed that KioskAR does not sufficiently support social interaction between players who do not know each other in advance, representing the need for something more to enhance the experience of a meaningful social interaction. There are also some problems regarding the usability of the kiosks (e.g., the difficulty of typing while looking at a kiosk and fixing the AR view while there are slight changes in the location or the direction of a user), which we aim to fix in future work. In addition, we plan to perform additional user studies to measure the scalability of the approach as the number of kiosks and players grows.

\section{Competing Interests}

The author declares that he has no competing interests.

\section{Acknowledgments}

The author would like to thank Saeedeh Sadighjamali (a Ph.D. candidate of folklore studies in Memorial University in Canada) for rigorous proofreading of the paper. 


\section{References}

[1] Gartner, Gartner Says Worldwide Video Game Market to Total $\$ 93$ Billion in 2013, 2013, http://www.gartner.com/newsroom/id/ 2614915.

[2] A. Mulloni, D. Wagner, and D. Schmalstieg, "Mobility and social interaction as core gameplay elements in multi-player augmented reality," in Proceedings of the 3rd International Conference on Digital Interactive Media in Entertainment and Arts (DIMEA '08), pp. 472-478, ACM, September 2008.

[3] O. Oda, L. J. Lister, S. White, and S. Feiner, "Developing an augmented reality racing game," in Proceedings of the 2nd International Conference on Intelligent Technologies for Interactive Entertainment (INTETAIN '08), article 2, ICST (Institute for Computer Sciences, Social-Informatics and Telecommunications Engineering), 2008.

[4] M. Montola, J. Stenros, and A. Waern, Pervasive Games: Theory and Design, Morgan Kaufmann Publishers, Burlington, Mass, USA, 2009.

[5] L. Valente and B. Feij, A Survey on Pervasive Mobile Games, MCC07/13, Departamento de Informática, PUC-Rio, Rio de Janeiro, Brazil, 2013.

[6] J. Y. Kim, J. P. Allen, and E. Lee, "Alternate reality gaming," Communications of the ACM, vol. 51, no. 2, pp. 36-42, 2008.

[7] P. Lankoski, S. Heliö, J. Nummela, J. Lahti, F. Mäyrä, and L. Ermi, "A case study in pervasive game design: the songs of north," in Proceedings of the 3rd Nordic Conference on HumanComputer Interaction (NordiCHI '04), pp. 413-416, ACM, October 2004.

[8] Gartner Emerging Trends and Technologies Roadshow, Gartner Identifies Top Ten Disruptive Technologies for 2008 to 2012, 2008.

[9] H. Li, T. Daugherty, and F. Biocca, "Impact of 3-D advertising on product knowledge, brand attitude, and purchase intention: the mediating role of presence," Journal of Advertising, vol. 31, no. 3, pp. 43-57, 2002.

[10] A. D. Cheok, K. H. Goh, W. Liu et al., "Human Pacman: a mobile, wide-area entertainment system based on physical, social, and ubiquitous computing," Personal and Ubiquitous Computing, vol. 8, no. 2, pp. 71-81, 2004.

[11] W. Piekarski and B. Thomas, "ARQuake: the outdoor augmented reality gaming system," Communications of the ACM, vol. 45, no. 1, pp. 36-38, 2002.

[12] L. Valente, B. Feijo, and J. C. S. do Prado Leite, "Mapping quality requirements for pervasive mobile games," Requirements Engineering, pp. 1-29, 2015.

[13] K. J. L. Nevelsteen, A Survey of Characteristic Engine Features for Technology-Sustained Pervasive Games, Springer, Berlin, Germany, 2015.

[14] M. Flintham, S. Benford, R. Anastasi et al., "Where on-line meets on the streets: experiences with mobile mixed reality games," in Proceedings of the SIGCHI Conference on Human Factors in Computing Systems, pp. 569-576, ACM, Fort Lauderdale, Fla, USA, April 2003.

[15] S. Benford, M. Flintham, A. Drozd et al., "Uncle roy all around you: implicating the city in a location-based performance," in Proceedings of the International Conference on Advances in Computer Entertainment Technology (ACE '04), pp. 21-47, Singapore, June 2004.

[16] O. Rashid, W. Bamford, P. Coulton, R. Edwards, and J. Scheible, "PAC-LAN: mixed-reality gaming with RFID-enabled mobile phones," Computers in Entertainment, vol. 4, no. 4, article 4, 2006.
[17] A. Waern and K. P. Kesson, "IPerG position paper," in Proceedings of the 2nd International Conference on Pervasive Computing, Vienna, Austria, April 2004.

[18] R. A. Ballagas, S. G. Kratz, J. Borchers et al., "REXplorer: a mobile, pervasive spell-casting game for tourists," in Proceedings of the Extended Abstracts on Human Factors in Computing Systems (CHI '07), pp. 1929-1934, ACM, San Jose, Calif, USA, May 2007.

[19] J. Peitz, H. Saarenpää, and S. Björk, "Insectopia: exploring pervasive games through technology already pervasively available," in Proceedings of the 4th International Conference on Advances in Computer Entertainment Technology (ACE '07), pp. 107-114, ACM, June 2007.

[20] S. Consolvo, D. W. McDonald, T. Toscos et al., "Activity sensing in the wild: a field trial of UbiFit Garden," in Proceedings of the 26th Annual CHI Conference on Human Factors in Computing Systems (CHI '08), pp. 1797-1806, Florence, Italy, April 2008.

[21] S. Kang, J. Lee, H. Jang et al., "SeeMon: scalable and energyefficient context monitoring framework for sensor-rich mobile environments," in Proceedings of the 6th International Conference on Mobile Systems, Applications, and Services, pp. 267-280, ACM, June 2008.

[22] C. Matysczok, R. Radkowski, and J. Berssenbruegge, "ARbowling: Immersive and realistic game play in real environments using augmented reality," in Proceedings of the ACM SIGCHI International Conference on Advances in Computer Entertainment Technology (ACE '04), pp. 269-274, ACM, September 2004.

[23] B. Knoerlein, G. Székely, and M. Harders, "Visuo-haptic collaborative augmented reality ping-pong," in Proceedings of the 4th International Conference on Advances in Computer Entertainment Technology, pp. 91-94, ACM, June 2007.

[24] A. D. Cheok, X. Yang, Z. Z. Ying, M. Billinghurst, and H. Kato, "Touch-space: mixed reality game space based on ubiquitous, tangible, and social computing," Personal and Ubiquitous Computing, vol. 6, no. 5-6, pp. 430-442, 2002.

[25] A. D. Cheok, W. Wang, X. Yang et al., "Interactive theatre experience in embodied + wearable mixed reality space," in Proceedings of the International Symposium on Mixed and Augmented Reality (ISMAR '02), pp. 59-68, October 2002.

[26] I. Lindt and W. Broll, "NetAttack-first steps towards pervasive gaming," ERCIM News, vol. 57, pp. 49-50, 2004.

[27] J. Michelsen and S. Bjrk, The Rooms-Creating Immersive Experiences Through Projected Augmented Reality, Foundations of Digital Games, 2014.

[28] S. Benford, D. Rowland, M. Flintham et al., "Life on the edge: supporting collaboration in location-based experiences," in Proceedings of the SIGCHI Conference on Human Factors in Computing Systems (CHI '05), pp. 721-730, ACM, Portland, Ore, USA, April 2005.

[29] Y.-C. Chang, J.-L. Lo, C.-J. Huang et al., "Playful toothbrush: ubicomp technology for teaching tooth brushing to kindergarten children," in Proceedings of theSIGCHI Conference on Human Factors in Computing Systems (CHI '08), pp. 363-372, ACM, Florence, Italy, April 2008.

[30] M. Montola, J. Stenros, and A. Waern, Pervasive Games. Theory and Design: Experiences on the Boundary between Life and Play, Morgan Kaufmann, 2009.

[31] S. Bjrk, J. Falk, R. Hansson, and P. Ljungstrand, "Pirates! using the physical world as a game board," in Proceedings of the Interact, pp. 423-430, Tokyo, Japan, July 2001. 
[32] C. Magerkurth, T. Engelke, and M. Memisoglu, "Augmenting the virtual domain with physical and social elements: towards a paradigm shift in computer entertainment technology," Computers in Entertainment, vol. 2, no. 4, p. 12, 2004.

[33] Y. N. Chang, R. K. C. Koh, and H. B. L. Duh, "Handheld AR gamesA triarchic conceptual design framework," in Proceedings of the IEEE International Symposium on Mixed and Augmented Reality-Arts, Media, and Humanities (ISMAR-AMH'11), pp. 2936, Basel, Switzerland, October 2011.

[34] Y. Xu, M. Gandy, S. Deen et al., "BragFish: exploring physical and social interaction in co-located handheld augmented reality games," in Proceedings of the International Conference on Advances in Computer Entertainment Technology (ACE '08), pp. 276-283, ACM, Yokohama, Japan, December 2008.

[35] D.-N. T. Huynh, K. Raveendran, Y. Xu, K. Spreen, and B. MacIntyre, "Art of defense: a collaborative handheld augmented reality board game," in Proceedings of the ACM SIGGRAPH Symposium on Video Games, pp. 135-142, ACM, August 2009.

[36] T. Jung, N. Chung, and M. C. Leue, "The determinants of recommendations to use augmented reality technologies: the case of a Korean theme park," Tourism Management, vol. 49, pp. 75-86, 2015.

[37] S. Jung, S. Kim, and S. Kim, "Augmented reality-based exhibit information personalized service architecture through spectator's context analysis," International Journal of Multimedia and Ubiquitous Engineering, vol. 8, no. 4, pp. 313-320, 2013.

[38] D. Marimon, C. Sarasua, P. Carrasco et al., MobiAR: Tourist Experiences through Mobile Augmented Reality, Telefonica Research and Development, Barcelona, Spain, 2010.

[39] E. Hering, Outlines of a Theory of the Light Sense, University of Chicago Press, Chicago, Ill, USA, 1964.

[40] Y. A. Sekhavat and O. Hoeber, "Visualizing association rules using linked matrix,graph, and detail views," International Journal of Intelligence Science, vol. 03, no. 1, pp. 34-49, 2013.

[41] T. Olsson, T. Kärkkäinen, E. Lagerstam, and L. Ventä-Olkkonen, "User evaluation of mobile augmented reality scenarios," Journal of Ambient Intelligence and Smart Environments, vol. 4, no. 1, pp. 29-47, 2012.

[42] A. M. Von Der Pütten, J. Klatt, S. Ten Broeke et al., "Subjective and behavioral presence measurement and interactivity in the collaborative augmented reality game TimeWarp," Interacting with Computers, vol. 24, no. 4, pp. 317-325, 2012.

[43] B. G. Witmer and M. J. Singer, "Measuring presence in virtual environments: a presence questionnaire," Presence: Teleoperators and Virtual Environments, vol. 7, no. 3, pp. 225-240, 1998.

[44] F. Biocca, C. Harms, and J. Gregg, "The networked minds measure of social presence: pilot test of the factor structure and concurrent validity", in Proceedings of the 4th Annual International Workshop on Presence, pp. 1-9, Philadelphia, Pa, USA, May 2001.

[45] P. Vorderer, S. Knobloch, and H. Schramm, "Does entertainment suffer from interactivity? the impact of watching an interactive tv movie on viewers' experience of entertainment," Media Psychology, vol. 3, no. 4, pp. 343-363, 2001.

[46] N. Ravaja, T. Saari, M. Turpeinen, J. Laarni, M. Salminen, and M. Kivikangas, "Spatial presence and emotions during video game playing: does it matter with whom you play?" Presence: Teleoperators and Virtual Environments, vol. 15, no. 4, pp. 381392, 2006.

[47] P. Vorderer, W. Wirth, F. R. Gouveia et al., "MEC spatial presence questionnaire (MEC-SPQ): short documentation and instructions for application," Report to the European Community, Project Presence: MEC (IST-2001-37661), 3, 2004.

[48] D. Weibel and B. Wissmath, "Immersion in computer games: the role of spatial presence and flow," International Journal of Computer Games Technology, vol. 2011, Article ID 282345, 14 pages, 2011.

[49] M. E. C. Santos, J. Polvi, T. Taketomi, G. Yamamoto, C. Sandor, and H. Kato, "Toward standard usability questionnaires for handheld augmented reality," IEEE Computer Graphics and Applications, vol. 35, no. 5, pp. 66-75, 2015.

[50] Y. S. Ryu and T. L. Smith-Jackson, "Reliability and validity of the mobile phone usability questionnaire (MPUQ)," Journal of Usability Studies, vol. 2, no. 1, pp. 39-53, 2006.

[51] W. C. Leung, "How to design a questionnaire," Student BMJ, vol. 9, no. 11, pp. 187-189, 2001. 


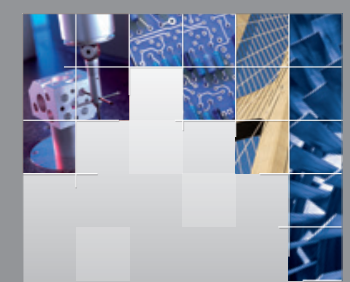

\section{Enfincering}
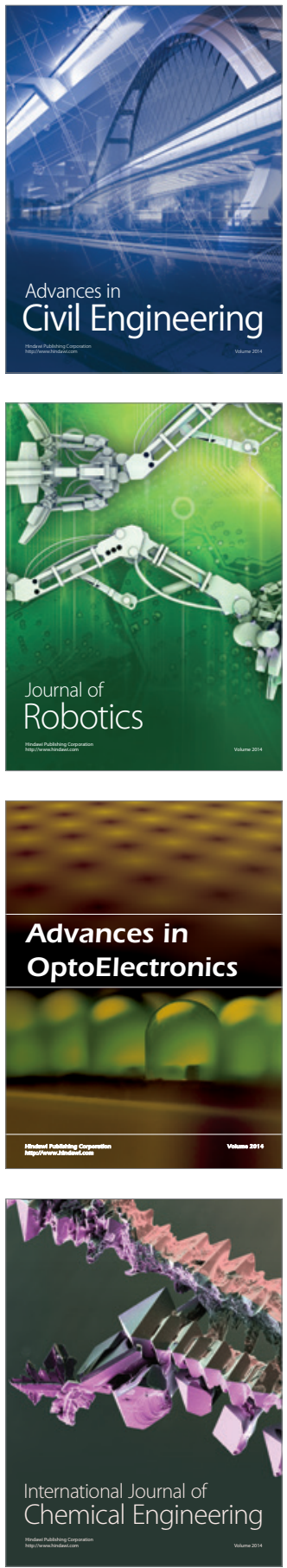

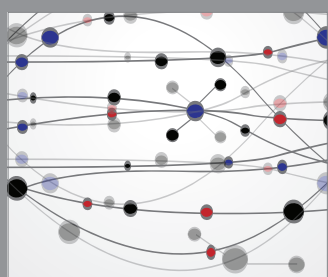

The Scientific World Journal

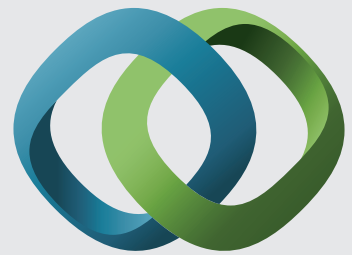

\section{Hindawi}

Submit your manuscripts at

http://www.hindawi.com
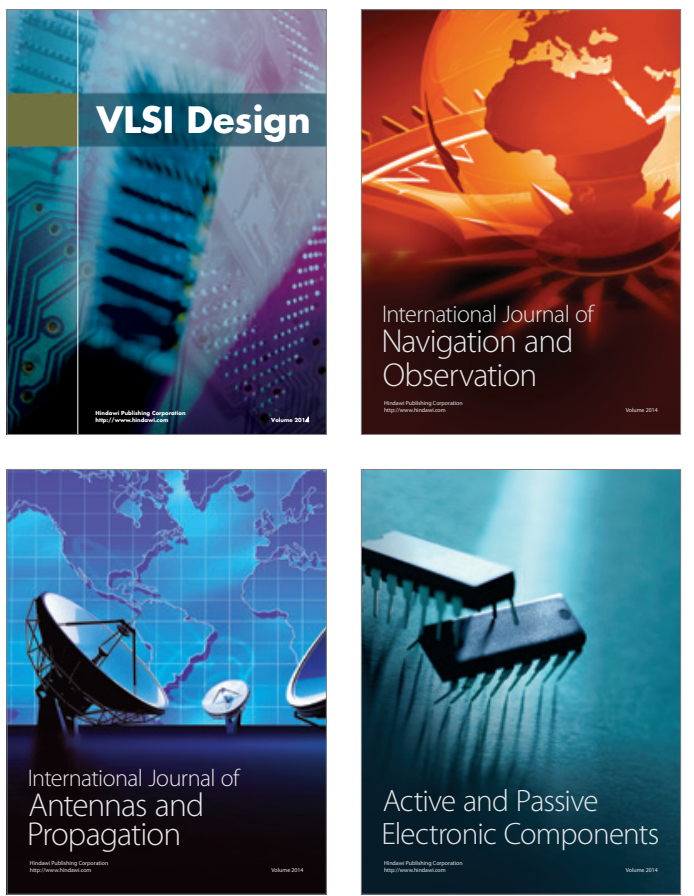
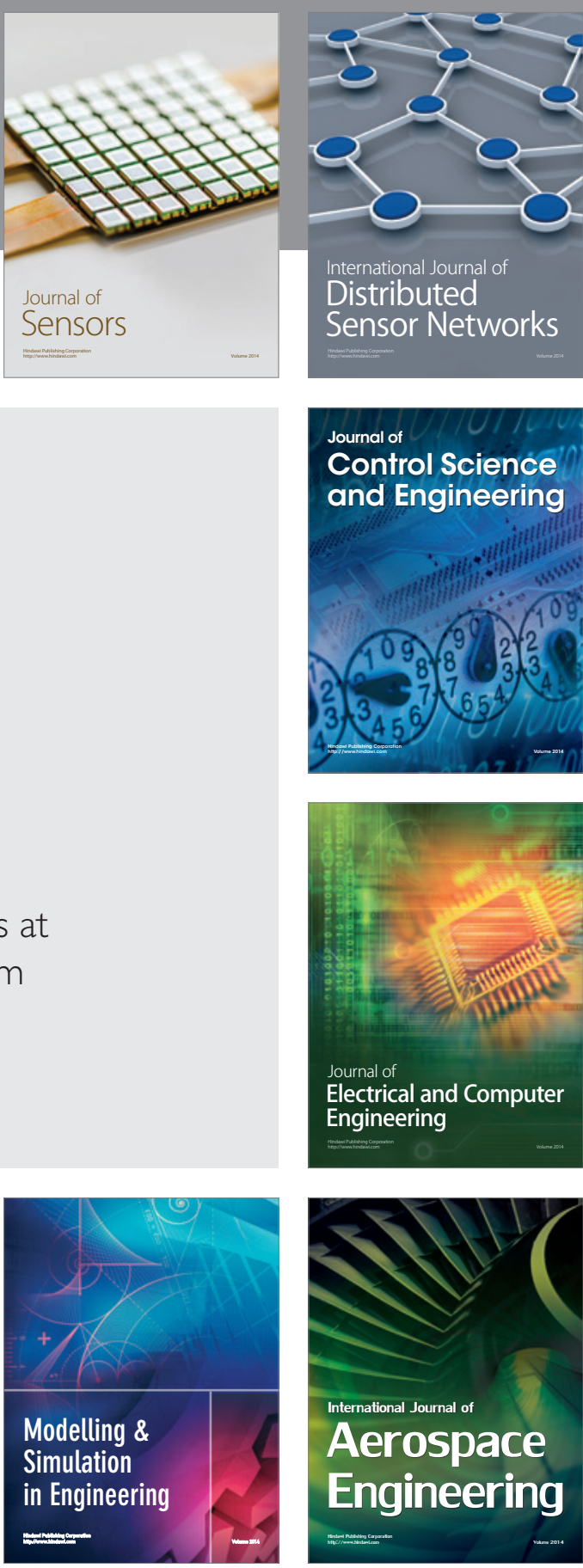

International Journal of

Distributed

Sensor Networks

Journal of

Control Science

and Engineering
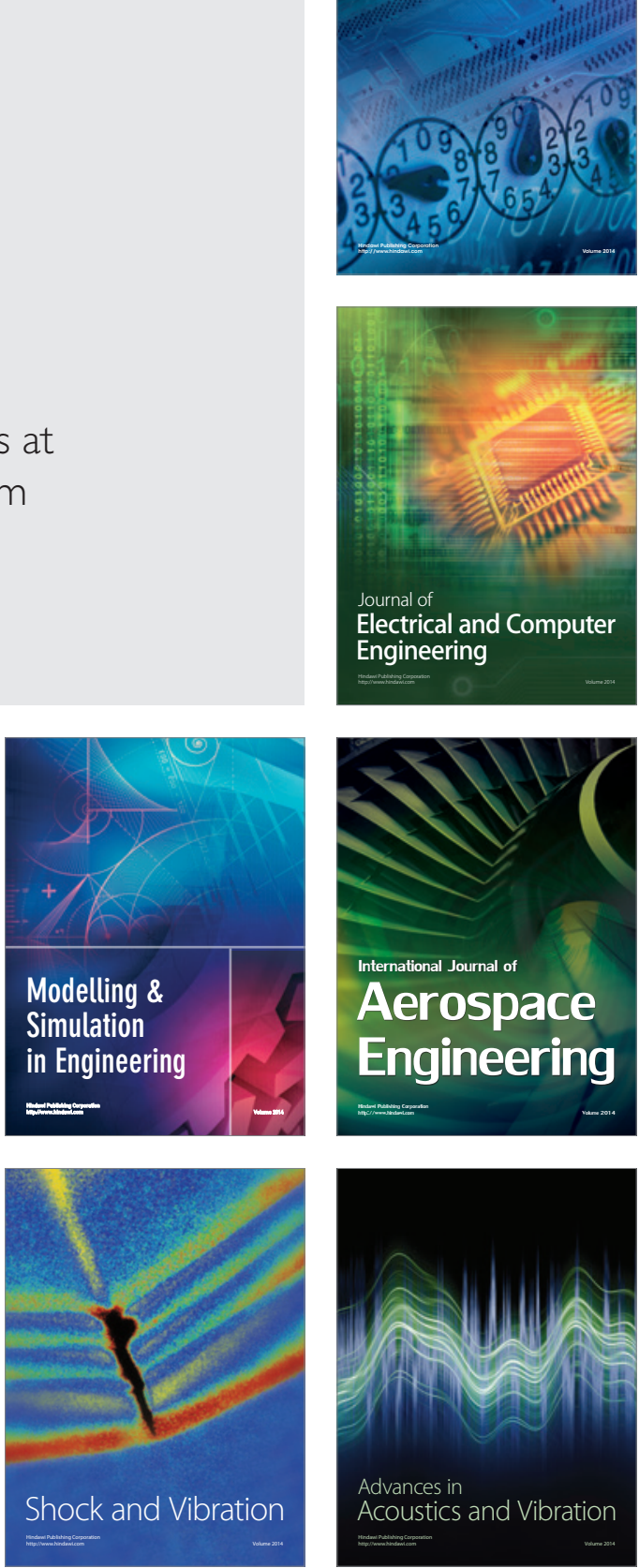